\title{
THE FIRST ADRIATIC FINDING OF SPELEOGOBIUS LLORISI (ACTINOPTERYGII: GOBIIFORMES: GOBIIDAE)
}

\author{
Marcelo KOVAČIĆ ${ }^{1 *}$ and Igor GLAVIČIĆ ${ }^{2}$ \\ 'Natural History Museum Rijeka, Rijeka, Croatia \\ ${ }^{2}$ Department of Marine Studies, University of Split, Split, Croatia
}

Kovačić M., Glavičić I. 2019. The first Adriatic finding of Speleogobius llorisi (Actinopterygii: Gobiiformes: Gobiidae). Acta Ichthyol. Piscat. 49 (2): 181-184.

\begin{abstract}
In June 2018 two specimens of recently described fish Spelegobius llorisi Kovačić, Ordines et Schliewen, 2016, were collected at Hvar Island in the central Adriatic Sea at $52 \mathrm{~m}$ depth during a SCUBA diving fieldwork, aimed to quantitatively study fishes of rhodolith beds. The findings represent the third known record of this species and the first for the Adriatic Sea. The complete and intact material enabled a study of colouration and morphological details not recorded in the damaged type material from a beam trawl.
\end{abstract}

Keywords: first record, Speleogobius llorisi, rhodolith beds, deep diving, Mediterranean

\section{INTRODUCTION}

Speleogobius llorisi Kovačić, Ordines et Schliewen, 2016 was recently described from six specimens collected from the circalittoral beds of red algae at a depth range of 46-69 $\mathrm{m}$ off the Balearic Islands, western Mediterranean by beam trawl sampling (Kovačić et al. 2016). A single specimen of this species was soon after reported from the Aegean Sea, collected by electronic closed circuit rebreather diving at a depth of $43 \mathrm{~m}$ (Engin et al. 2017).

In June 2018 two specimens of Speleogobius llorisi were collected at Cape Tatinja on the north side of the Island of Hvar in the central Adriatic Sea during preliminary fieldwork for the quantitative study of Adriatic fishes of rhodolith beds and stored in the collection of the Natural History Museum Rijeka. The aims of the present paper were: 1) to report the first record of S. llorisi in the Adriatic Sea and third in total for this species, 2) to improve the species' original description (Kovačić et al. 2016) of the colouration and morphological traits by using intact specimens.

\section{MATERIAL AND METHODS}

The specimens of Speleogobius llorisi were collected by hand net and anaesthetic Quinaldine using trimix diving at the first of the fieldworks aimed for quantitative assessment of cryptobenthic ichthyofauna on Mediterranean rhodolith beds that lasted from 11 through 16 June 2018. The diving technique and the quantitative method for collecting fishes followed Glavičić and Kovačić (2016), based on the use of anaesthetic Quinaldine at delimited bottom quadrates of $1 \mathrm{~m}^{2}$. The collected specimens were euthanized after
SCUBA dives by the method of over-anaesthetization with Quinaldine. The morphological diagnosis is a minimum combination of characters that positively identify fresh or preserved specimens of S. llorisi among species of family Gobiidae in the CLOFNAM area (Miller 1986, Kovačić and Patzner 2011, Kovačić et al. 2016 and references therein). The terminology of the lateral-line system, morphometric and meristic methods, meristic abbreviations, and staining techniques were as in Kovačić et al. (2016). The material (PMR VP4357 and PMR VP4356) was deposited in the Prirodoslovni muzej Rijeka (PMR).

\section{RESULTS}

Material collected (standard length + caudal fin length): 1 male, $26.7+5.6 \mathrm{~mm}$. PMR VP4357, 1 female, $25.8+5.6 \mathrm{~mm}$, PMR VP4356, both Tatinja, Hvar, Croatia, Adriatic Sea $\left(43^{\circ} 13.017^{\prime} \mathrm{N}, 16^{\circ} 38.265^{\prime} \mathrm{E}\right), 13$ June 2018, , collected by I. Glavičić and M. Kovačić (Figs. 1, 2).

Species diagnosis. (1) suborbital row of sensory papillae $a$ present; (2) head with anterior oculoscapular and preopercular canals, carrying pores $\sigma, \lambda, \kappa, \alpha, \beta, \rho$, and $\gamma, \delta, \varepsilon$ respectively, posterior oculoscapular canal absent; (3) predorsal area scaly; (4) pelvic fins united into disc, posteriorly emarginated and without anterior membrane; (5) scales in lateral series 28 or 29 ; (6) scales in transverse series 6 ; (7) snout long, equal or longer than eye, 1.0-1.1 in eye length (1.0 in both present specimens), dorsal profile of snout gently sloping; (8) lower lip ends anteriorly slightly in front of upper lip; (9) head length as percentage of standard length: $27.3 \%-30.0 \%$ adults, $32.2 \%$ juvenile (27.3\% and $28.7 \%$ in present specimens); (10) body depth 


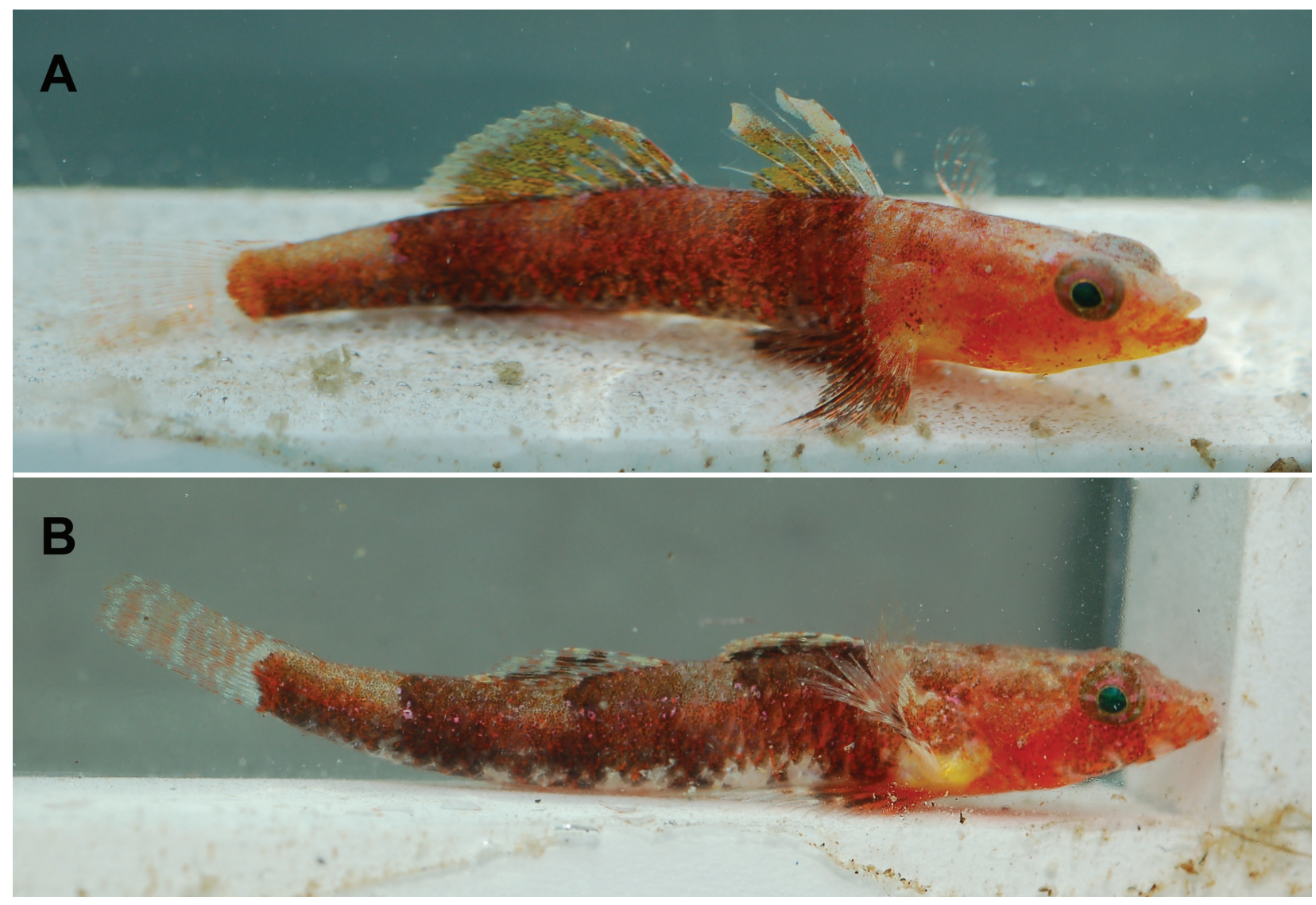

Fig. 1. Speleogobius llorisi alive colouration:(A) male, 26.7 +5.6 mm, PMR VP4357,(B) female, 25.8 + 5.6 mm, PMR VP4356,

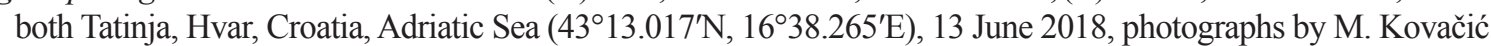

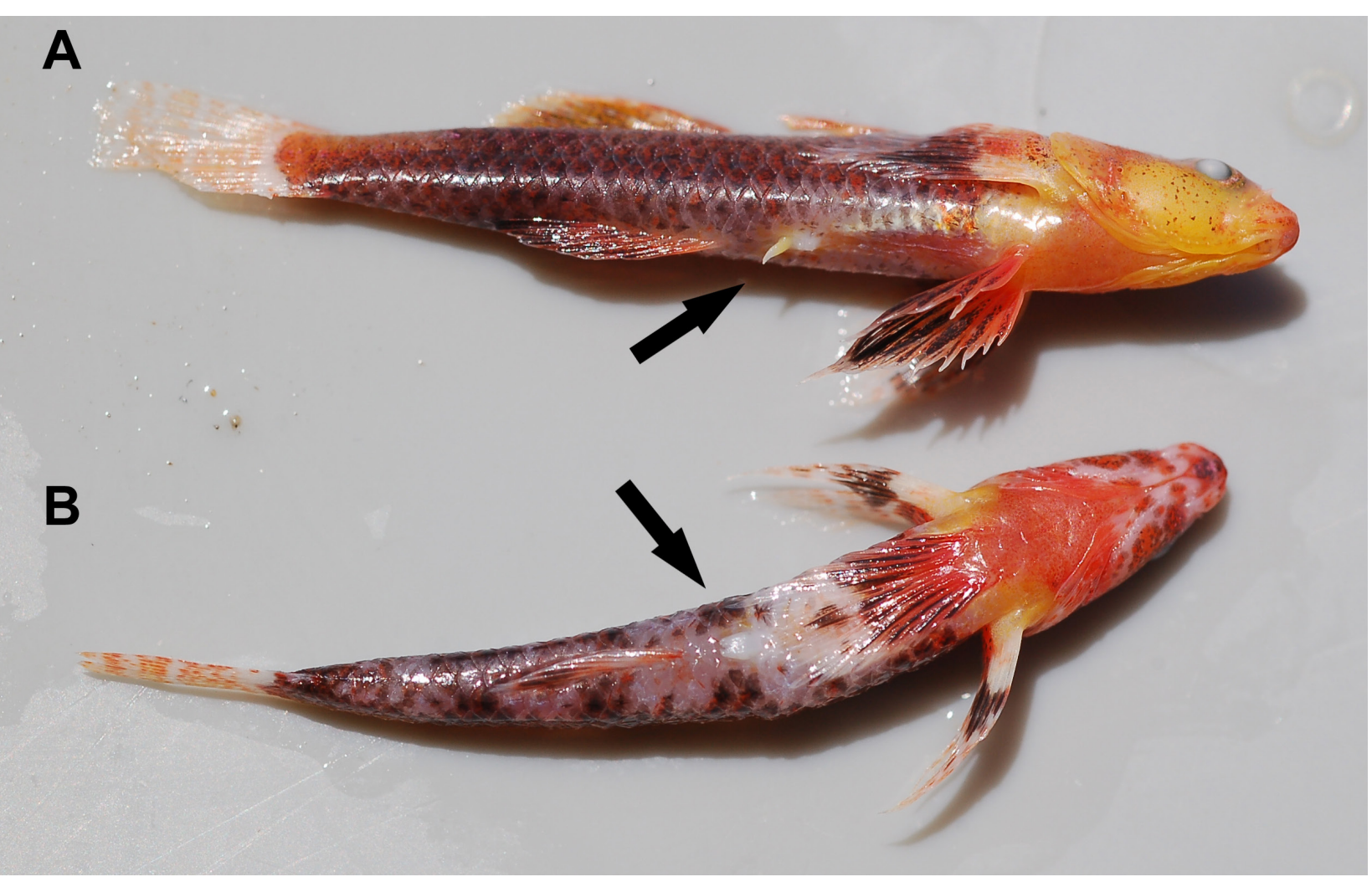

Fig. 2. Speleogobius llorisi freshly preserved with visible urogenital papillae: (A) male, $26.7+5.6 \mathrm{~mm}$, PMR VP4357, (B) female, $25.8+5.6 \mathrm{~mm}$, PMR VP4356, both Tatinja, Hvar, Croatia, Adriatic Sea $\left(43^{\circ} 13.017^{\prime} \mathrm{N}, 16^{\circ} 38.265^{\prime} \mathrm{E}\right), 13$ June 2018; photograph by M. Kovačić 
measured at pelvic fin origin as percentage of standard length: $15.0 \%-16.8 \%$ (15.4\% and $15.5 \%$ in presently reported specimens); (11) eye diameter (as percentage of standard length): $6.9 \%-7.7 \%(7.1 \%$ and $7.7 \%$ in present specimens); (12) colouration of head and body to pectoral and pelvic fins, orange red in females, ventrally yellow, laterally orange yellow in males, rest of body brown to reddish brown.

Description of newly collected specimens. Colour of alive material (Fig. 1). Female head and anterior body to pectoral and pelvic fin base orange red, rest of body brown to reddish brown with three brown vertical bands below D1, anterior part of D2 and behind posterior edge of D2, alternating with pale reddish-brown bands, first in front of D1, last on posterior part of caudal peduncle, better visible dorsally. Predorsal area reddish brown, underside of head, cheek and opercle red with poorly visible white parts. Area close to lower end of pectoral base yellow, prepelvic area orange red. Ventral midline and belly whitish. Dorsal fins with brown ill-defined band in middle part and rest of fin transparent and dotted with red brown dots. Caudal fin at base with continuing brown colouration from caudal peduncle, followed by three ill-defined orange vertical bands. Anal fin transparent with brown area posteriorly. Pectoral fin with orange mark in anterior upper part, fin whitish below and above it, following by brown mark in lower part of fin middle, rest of fin above and posterior to brown mark transparent with scattered red-brown dots. Pelvic fin with red orange base, dark middle part and white or transparent posterior part. Male head and anterior body to pectoral and pelvic fin base ventrally yellow, laterally orange yellow and dorsally pale to reddish, including predorsal area. Rest of body brown to reddish brown with three brown vertical bands below D1, anterior part of D2 and behind posterior edge of D2 alternating with pale reddish-brown bands, first in front of D1, last on posterior part of caudal peduncle, better visible dorsally. Pale parts of upper part of body less visible than in female, giving more uniform impression of male brown colouration than female. Ventral midline and belly without clear whitish area and mostly brown, different from female. Dorsal fins mostly yellowish brown with pale edge at fin tips. Caudal fin at base similar as female. Anal fin reddish brown. Pectoral fin with orange mark in anterior upper part, fin whitish below and above it, followed by brown mark larger than in female, rest of fin above and posterior to brown mark transparent with scattered red brown dots. Pelvic fin with red orange base, dark brown rest of fin and white or transparent tips.

Fin and squamation meristics: D1 VI; D2 I/7; A I/6; C 11 branched rays, 15 segmented rays; V I/5 + 5/I. Scales in lateral series 28 and 29, in transverse series 6 , scales along dorsal midline ctenoid 7, scales along ventral midline 3 .

Lateral line system: Head canals and rows of sensory papillae with anterior dorsal area with additional rows of papillae now recorded in intact specimens: row $o$ as single papilla, two papillae of row $g$ behind it, longitudinally arranged, row $m$ laterally below posterior papilla of row $g$ (Fig. 3).

Ecological data. Two reported specimens were collected in the same collecting quadrate with $80 \%$ biocover of rhodolith beds over detritic coarse sand on the nearly horizontal bottom at $52 \mathrm{~m}$ depth. Speleogobius llorisi was collected in the same quadrate together with specimens of Odondebuenia balearica (Pellegrin et Fage, 1907) and Vanneaugobius dollfusi Brownell, 1978.

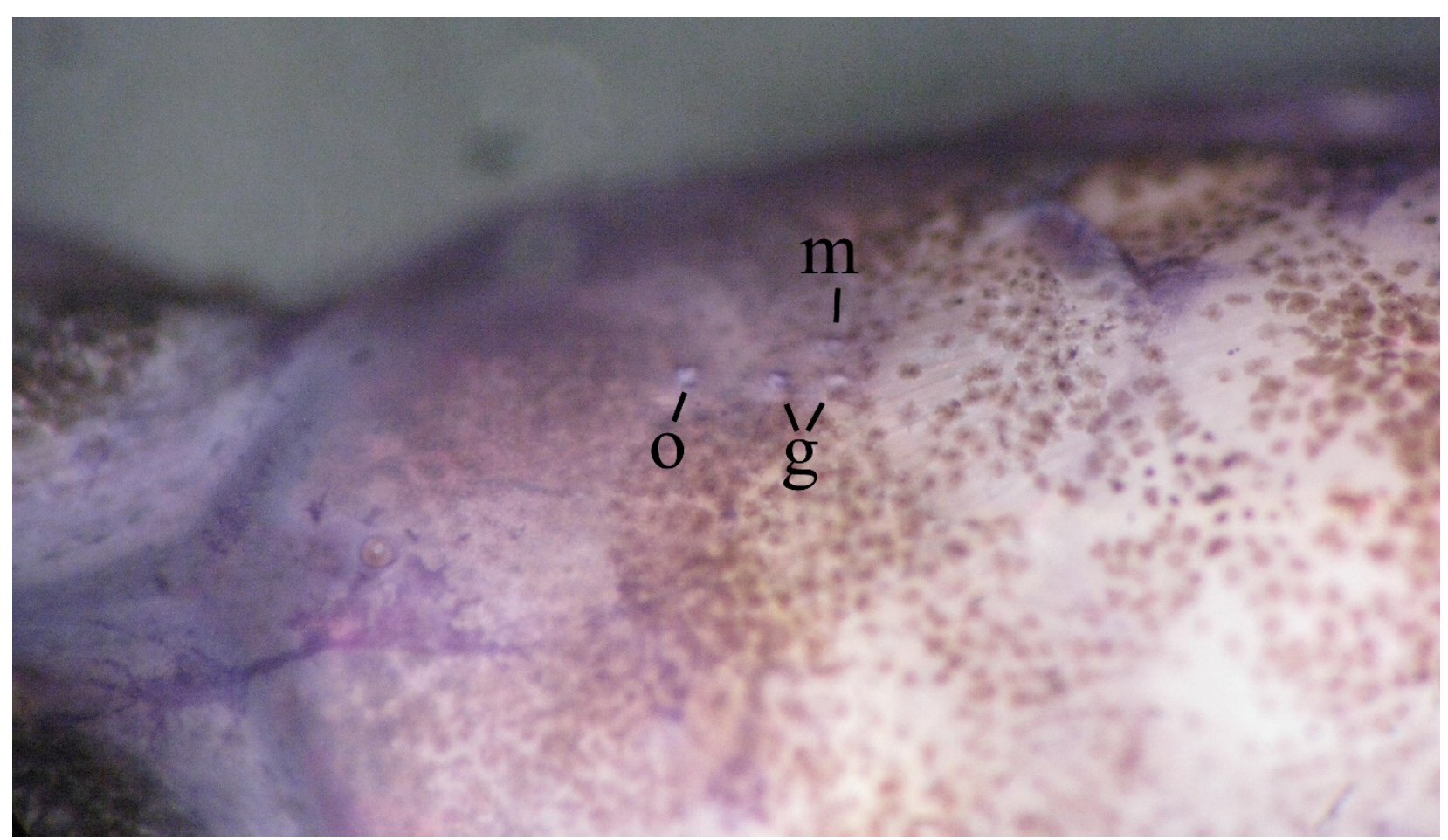

Fig. 3. Speleogobius llorisi female, $25.8+5.6 \mathrm{~mm}$, PMR VP4356; anterior dorsal rows $o$, $g$, and $m$; photograph by M. Kovačić 


\section{DISCUSSION}

The presently reported specimens showed sexual dichromatism, with male being more intensively and uniformly coloured. The freshly collected female from the original description (Kovačić et al. 2016) had significantly altered colouration from the natural condition i.e., from the alive and freshly preserved present specimen (fig. 2 in Kovačić et al. 2016, Figs. 1B and 2B in this paper) due to the damages (scale loss, fin membrane destruction, etc.) caused by the collecting method, which resulted in the altered species fresh colouration description provided in the original description. Alive colouration of male described in Engin et al. (2017) match the presently reported colouration pattern, however the specimen in the natural habitat had much less intensive colouration compared to the presently reported specimen in aquarium, missing yellow colour of head and intensive brown colouration along body (fig. 2b in Engin et al. 2017, Fig. $1 \mathrm{~A}$ in this paper), resembling more female colouration of the presently reported study. It is also possible that the present intensive colouration of the male is seasonal i.e., nesting colouration of a male in the breeding season. The data on lateral line system provided in the original description (Kovačić et al. 2016) were amended by the details from the intact new material. Anterior dorsal rows of sensory papillae, presented as more reduced in the original description, are usually first to be lost or not possible to be seen in damaged material descriptions (Kovačić et al. 2017, Engin et al. 2017). The species diagnosis was modified in the colouration character by live colouration of both sexes and by the expanded range of the head length.

The collecting of small cryptic fishes at circalittoral bottoms is restricted to two methods: trawling with fishing nets of fine mesh size, like beam trawl (Kovačić et al. 2016) for soft sediment or collecting by divers using trimix diving since circalittoral depths are below the safe limit of compressed-air diving for hard bottoms (Glavičić and Kovačić 2016). Sampling with a beam trawl results in small fish being pressed inside the net by hard structured bycatch during trawling, and delicate morphological structure on the fish surface (e.g., scales, fin membranes, fin rays, lateral line system) are lost or damaged (see notes on damages in the description part of Kovačić et al. 2016, 2017). The collection of small fish specimens by divers is clearly advantageous for the study of morphological traits since those damages are avoided, and whenever possible, considering species abundance and chance to find it, the method should be expanded also on the soft sediments. However, the method is seriously limited when compared to trawling due to the depth that can be reached and to the surface of the bottom that can be sampled.
With the presently reported new record, the number of Adriatic gobiid species is 47. Other changes of the known Adriatic gobiid diversity since the checklist of Kovačić (2005) was the exclusion of Adriatic Sea from the distribution of Knipowitschia caucasica (Berg, 1916) (see Kottelat and Freyhof 2007) and the description of Gobius incognitus Kovačić et Šanda, 2016, which left the total number of species unchanged.

\section{ACKNOWLEDGEMENTS}

This work has been supported in part by Croatian Science Foundation under the project IP-2016-06-9884.

\section{REFERENCES}

Engin S., Oruç A.Ç., Seyhan D., Irmak E. 2017. New records of Speleogobius trigloides Zander et Jelinek, 1976 and S. llorisi Kovačić, Ordines et Schliewen, 2016 (Osteichthyes: Gobiidae) in the Aegean Sea. Journal of Applied Ichthyology 33 (5): 1015-1017. DOI: $10.1111 /$ jai.13413

Glavičić I., Kovačić M. 2016. A quantitative sampling method for assessment of deep cryptobenthic ichthyofauna using trimix diving. Acta Ichthyologica et Piscatoria 46 (1): 43-47. DOI: $10.3750 /$ AIP2016.46.1.06

Kottelat M., Freyhof J. 2007. Handbook of European freshwater fishes. Publications Kottelat, Cornol, Switzerland and Freyhof, Berlin, Germany.

Kovačić M. 2005. An annotated checklist of the family Gobiidae in the Adriatic Sea. Annales, Series Historia Naturalis 15 (1): 21-44.

Kovačić M., Ordines F., Schliewen U.K. 2016. A new species of Speleogobius (Teleostei: Gobiidae) from the Western Mediterranean Sea. Zootaxa 4066 (3): 301309. DOI: 10.11646/zootaxa.4066.3.6

Kovačić M., Ordines F., Schliewen U.K. 2017. A new species of Buenia (Teleostei: Gobiidae) from the western Mediterranean Sea, with the description of this genus. Zootaxa 4250 (5): 447-460. DOI: 10.11646/ zootaxa.4250.5.3

Kovačić M., Patzner R.A. 2011. North-eastern Atlantic and Mediterranean gobies. Pp. 177-206. In: Patzner R.A., Van Tassell J.L., Kovačić M., Kapoor B.G. (eds.) The biology of gobies. Science Publishers, CRC Press, Taylor and Francis Group, New York, NY, USA.

Miller P.J. 1986. Gobiidae. Pp. 1019-1085. In: Whitehead P.J.P., Bauchot M.-L., Hureau J.-C., Nielsen J., Tortonese E. (eds.) Fishes of the North-eastern Atlantic and the Mediterranean Vol. 3. UNESCO Paris, France.

Received: 21 August 2018

Accepted: 15 October 2018

Published electronically: 15 June 2019 